\title{
Can the Weight Reduction Program Improve Obese Thai Adolescents' Body Mass Index and Autonomous Motivation?
}

\author{
Kanlayanee $\mathbf{N}^{1}$, Tuicomepee A $^{2}$, Kiamjarasrangsi $\mathbf{W}^{3}$, Sithisarankul $\mathbf{P}^{4}$
}

\begin{abstract}
Introduction: Overweight and obesity has impacted both the physiological and psychological health of children and adolescents. Evidence of cross-cultural studies has showed mixed results regarding weight reduction program (WRPs) based on self-determination theory (SDT) and social cognitive theory (SCT) affecting students with overweight and obesity. This study examined the effectiveness of a WRP on body mass index (BMI) and autonomous motivation in overweight and obese Thai adolescents. Material and Methods: An experimental study with intervention and control groups was employed. Participants were 304 Thai obese $7^{\text {th }}$ - to $12^{\text {th }}$-grade students, ranging in age from 12 to 19 years. The intervention group was assigned to a program based on SDT and SCT, consisting of (1) a 12-week weight control phase and (2) a 12-week follow-up phase. The control group was assigned to a general health education program. The data were collected via psychometric questionnaires and anthropometric data. Results: There were no statistical differences in adjusted means of BMI and autonomous motivation of physical activity and dietary intake occurred among participants in the two groups. Compared to those in the control group, participants in the intervention group showed a 0.4 smaller increase in $\mathrm{BMI}$ and a 0.4 greater decrease in autonomous motivation of dietary intake. Conclusion: The WRP based on SDT and SCT showed no apparent effectiveness in improving BMI or autonomous motivation among these participants. Future studies should incorporate program that effectively harmonize with core school teaching activities and schedules.
\end{abstract}

Key words: weight reduction program, self-determination theory, social cognitive theory, body mass index, autonomous motivation

\section{Abbreviations}

BMI: body mass index, BREQ-2: Behavioral Regulation in Exercise Questionnaire-2, CONSORT: Consolidated Standards of Reporting Trials, DSR: dietary self-regulation, RAl: Relative Autonomy Index, MI: motivational interview, RAMI: Relative Autonomous Motivation Index, SCT: social cognitive theory, SDT: self-determination theory, WRP: weight reduction program
${ }^{1}$ Ms. Kanlayanee No-in, RN, BNS, MPH (candidate Ph.D. student), Department of Preventive and Social Medicine, Faculty of Medicine, ${ }^{2} \mathrm{Dr}$. Arunya Tuicomepee, BS, MA, PhD, Associate Professor, Faculty of Psychology, ${ }^{3}$ Dr. Wiroj Jiamjarasrangsi, MD, DTM\&H, MPH, PhD Associate Professor, Department of Preventive and Social Medicine, Faculty of Medicine, ${ }^{4} \mathrm{Dr}$. Pornchai Sithisarankul, MD, MPH, DrPH Professor, Department of Preventive and Social Medicine, Faculty of Medicine. All from the Chulalongkorn University, Bangkok, 10330, Thailand

\section{Address for correspondence \\ Pornchai Sithisarankul \\ Chulalongkorn University, \\ Bangkok, 10330, Thailand \\ Tel No;+66-8-9886-7824 \\ E-mail: psithisarankul@gmail.com}

\section{Acknowledgements: None}

Funding: The study was supported by the Ratchadapisek-sompotch Fund, Faculty of Medicine, Chulalongkorn University, grant number RA57/034

Conflict of Interest: None

Permission from IRB: Yes

\section{How to cite}

Kanlayanee N, Tuicomepee A, Kiamjarasrangsi W, Sithisarankul P. Can the Weight Reduction Program Improve Obese Thai Adolescents' Body Mass Index and Autonomous Motivation? J Nepal Paediatr Soc 2017;37(1):10-20.

doi: http://dx.doi.org/10.3126/jnps.v37i1.16938

This work is licensed under a Creative Commons Attribution 3.0 License. 


\section{Introduction}

hildhood and adolescent overweight and obesity have increased rapidly in both developed and developing countries $1,2,3,4$. Obesity rates in children and adolescents in Thailand were $5.8 \%, 6.7 \%$, and $9.7 \%$ in 1995, 2001, and 2008-2009, respectively ${ }^{5}$. Childhood and adolescence obesity has both short- and long-term physical and psychosocial impacts ${ }^{6,7}$. It can progress into adult obesity ${ }^{7,8}$ resulting in an increased rate of chronic disease in adulthood ${ }^{7}$, Schools offer important settings for implementing weight reduction programs (WRPs) as they can reach a large number of youths $s^{9,10,11,12}$. WRPs help prevent and treat obesity in adolescents ${ }^{13}$. Motivation is a strong predictor of weight reduction in children and adolescents in $\mathrm{WRPs}^{13}$. Previous school-based interventions demonstrated that youth who participate in enjoyable and engaging activities to enhance autonomous motivation experience more positive results in body mass index (BMI), healthy diet, and physical activity ${ }^{10,14,15}$. Few studies have evaluated autonomous motivation for physical activity and dietary intakes in school-age (particularly secondary school) students, but their findings are appropriate for Western contexts $^{14,15,16,17}$

Social cognitive theory (SCT $)^{9,10,11}$ and selfdetermination theory (SDT) ${ }^{17,18}$ have been widely used in school-based WRPs and in Western contexts. Grounded $\mathrm{SCT}^{19}$ came from the triadic reciprocal determinism evident in interaction patterns among personality, behaviors, and environments. A person's ability to originate and direct actions for given purposes affecting his or her environment and behaviors is called personal agency and termed self-efficacy ${ }^{20}$. Self-efficacy refers to a person's belief in his or her ability to achieve behaviors and is reflected in the capacity to control his or her motivation, behavior, and environment. Self-regulation is directly affected by self-efficacy and a correlate of activity. Self-regulation involves individual processes to attain goals and behaviors ${ }^{19}$, thereby enhancing skill development and motivational activities. Empirical studies of WRP based on SCT found positive outcomes, such as reducing BMI and participating in activities ${ }^{9,10,11}$.

SCT's concept is rather similar to self-determined motivation from SDT, which refers to people's capacity to reflect upon and engage in tasks of their choosing, not because of external rewards or pressures ${ }^{21}$. Few studies have applied SCT to school interventions in Thailand; those that have showed inconsistent impacts on weight measures and psychometric variables ${ }^{22,23,24}$. Results do not provide clear guidance for decreasing excessive weight through school-based programs ${ }^{22,23,24}$.
SDT could provide a useful framework for understanding individuals' task participation. SDT has been applied in studying health behavior interventions (e.g., physical activity and healthy diet), with some positive outcomes ${ }^{17,18,25}$. SDT identified two types of motivation-autonomous motivation and controlled motivation ${ }^{21,26}$ through six steps of continual motivation development: amotivation, external regulation, introjected regulation, identified regulation, integrated regulation, and intrinsic motivation. External through integrated regulation (the second to fifth types) rely on extrinsic motivation or a higher hierarchy development of controlled motivation ${ }^{21,27}$ whereas intrinsic motivation occurs through one's inner self or fundamental psychological needs-namely, autonomy, relatedness, and competence ${ }^{27}$. Autonomy is the need to experience individual actions resulting from self-endorsement and perceived choice; competence is the need to experience one's capability to control an environment and predict outcomes; and relatedness is the need to experience satisfaction through involvement with one's connectedness ${ }^{21}$.

WRP combines SDT and SCT to increase the intervention's effectiveness ${ }^{15}$. Previous studies incorporating both theories have demonstrated stronger relationships among self-determined motivation of physical activity, healthy diet, and maintained weight loss $^{14,15}$. However, no studies have yet applied both SDT and SCT to WRP for overweight and obese Thai secondary school students. It is hypothesized that, by participating in WRP based on SDT and SCT, these students will improve their BMI and autonomous motivation for physical activity and dietary intake. This study measures the effectiveness of WRP on BMI and autonomous motivation among such students.

\section{Materials and Methods}

This experimental study involved a pretest, posttest, follow-up with a control group for evaluating the effectiveness of school-based physical activity and dietary plans. Measurements were tested at weeks 0 , 12, and 24. The design and enrollment of this study followed Consolidated Standards of Reporting Trials (CONSORT) guidelines ${ }^{28}$, as shown in Figure 1.

The first step was a purposive sampling of two largest secondary schools in two districts with similar characteristics (e.g., number of students, health promotion school policy, and willingness to participate in the study) in the Secondary Educational Service Area Office 37 in the Nan Province in Thailand. One school was then randomly assigned into the intervention while the other into the control groups. In the third step, one 
classroom was simple randomly selected each for the $7^{\text {th }}$ - to $12^{\text {th }}$-grade classrooms in each school. Students with the BMI for age and sex more than or equal to the $85^{\text {th }}$ percentile when using $\mathrm{WHO}$ growth standard reference [WHO, 2007] $]^{29}$ and volunteer to participate with the allowance of the parents were recruited into the study. Those with the existing musculoskeletal and cardiovascular diseases were however excluded. Sample size was calculated by a formula for the two populations' means and relying on the data about the mean BMI for age and sex from Duangchan's study ${ }^{22}$. The possibility of $20 \%$ dropout was also compensated, resulting in 160 students per group. However, 10 and 6 students in control and intervention groups who were later detected to have normal BMI were excluded after baseline assessments. A total of 304 participants were then included in this study. These participants were mostly males (intervention group: $n=154,81$ males, $52.6 \%$; control group: $n=150,79$ males, $52.7 \%$ ) and aged between 12 to 19 years. The detailed data are presented in Figure 1 and Table 2. They were recruited upon individual and parental consent. The ethics of this study were approved by the Institutional Review Board of the Faculty of Medicine at Chulalongkorn University (IRB No. 253/56). The study ID of Thai Clinical Trials Registry (TCTR) was TCTR20130515001. The study began in July 2013 and finished in February 2014.

The WRP used in this study was a school-based curriculum developed by the authors that combined health education and physical exercise and used SCT and SDT for the program's scope. The program's contents and activities were multidisciplinary in nature and were contributed by a nurse, two health promotion experts, a psychologist, a dietitian, an exercise expert, and a school teacher. The school teacher was a health education and physical exercise teacher who cooperated on lesson plan and content development, and was the sole teacher during eight sessions. The program included two phases. The first 12-week weight-control phase consisted of eight teaching sessions (overweight and obesity, dietary, physical activity, weight control, and negative emotional management) led by the school teacher (40 to 60 minutes each), once a week for the first four sessions and once every two weeks for the last four sessions. In addition, the 30-minute free-choice physical activity sessions were offered three times a week, while participants engaged in their favorite exercises and physical activity as a group or on their own during exercise times. Moreover, they were asked to take notes on their daily physical activity and dietary intakes. The second 12-week follow-up phase, there was no structured activity except for some stimulation techniques such as individual and group meetings, supports, monitoring, good communication, and group counseling. Examples of the WRP component details are presented in Table 1.

\section{Measures}

1. Outcomes Measures: The primary outcome was BMI, which was used to evaluate the effectiveness of this program. The secondary outcomes were the autonomous motivation of physical activity and dietary intakes.

2. Anthropometric Measures: Heights were measured to the nearest millimeter using a portable stadiometer. Weights (in kilograms) were measured using a portable scale; participants were weighed without shoes and in light clothing. $\mathrm{BMI}$ was calculated, and the WHO growth standard reference (WHO 2007) ${ }^{29}$ cut-points were determined as normal (BMI for age and sex $<85^{\text {th }}$ percentiles), overweight (BMI for age and $\operatorname{sex}^{3} 85^{\text {th }}$ percentiles to $<95^{\text {th }}$ percentiles), and obesity (BMI for age and sex ${ }^{3} 95^{\text {th }}$ percentiles).

3. Autonomous motivation Measures:

3.1 Behavioral Regulation in Exercise Questionnaire-2 (BREQ-2) 30: The BREQ-2 measures an individual's motivation toward exercise. Its 19 items use a rating scale $(0=$ not true for me; 4 = very true for me) for 5 factors of motivation: amotivation, external regulation, introjected regulation, identified regulation, and intrinsic motivation. In scoring the BREQ-2 ${ }^{16,31}$, the total mean of the 5 subscales is calculated using a 5-point motivation subscale separating each type of motivation. The Relative Autonomy Index (RAI) was used to evaluate the degree of relative autonomy given that the 5 motivation types are located along the self-determination continuum. The RAI is calculated by weighting each motivation subscale and summing the weighted scores: (amotivation multiplied by $-3)+$ (external regulation multiplied by -2 ) + (introjected regulation multiplied by -1 ) + (identified regulation multiplied by 2 ) + (intrinsic regulation multiplied by 3 ). The minimum RAI score is -24 , and the maximum score is +20 . Higher positive RAI scores indicate higher autonomous motivation whereas lower negative scores indicate lower autonomous motivation. The RAI is the composite score of relative autonomy. The BREQ-2 was validated on Thai adolescents. The reliability of each factor was $0.57,0.35,0.70,0.55$, and 0.83 , respectively, and overall it was 0.77 ; details have been reported elsewhere ${ }^{32}$. 
3.2 Dietary Self-Regulation (DSR) questionnaire ${ }^{33}$. The DSR measures the degree of a person's motivation for maintaining a healthy diet that is autonomous or self-determined. Its 15 items are measured using a 7-point rating scale (1 $=$ not true at all; 7 = very true) for 3 factors of motivation: autonomous motivation, externally controlled motivation, and amotivation. When scoring the $\mathrm{DSR}^{33}$, items in each of the 3 subscales are averaged to create separate scores for autonomous motivation, controlled motivation, and amotivation. These three subscale scores can be used separately. The Relative Autonomous Motivation Index (RAMI) can be calculated by subtracting the average of the externally controlled reasons from the average of the autonomous reasons. The minimum RAMI score is 1 , and the maximum score is 7. Higher positive RAMI scores indicate a higher autonomous motivation of eating. For the DSR validated on Thai adolescents, the reliability of each factor was $0.67,0.83$, and 0.81 , respectively, and overall was .82 ; details have been reported elsewhere ${ }^{32}$.

Statistical analysis: Descriptive statistics were used to describe participants' characteristics. Mean differences and adjusted mean differences of the dependent variables among the intervention and the control group at $12^{\text {th }}$ and $24^{\text {th }}$ weeks were compared using an independent $t$-test and simple linear regression analysis, respectively. Controlling confounders were done using a multiple linear regression analysis. The cut-off point for statistical significance was $p$ value $<.05$.

\section{Results}

Participants: Ultimately, 304 Thai overweight and obese secondary school students were recruited from the intervention and the control schools. Only daily school pocket money (Baht/day) differed between the two groups at the baseline. Data are presented in Table 2 . BMI: In the $12^{\text {th }}$ week of the program, the intervention group showed a significantly increase in BMI $0.4 \mathrm{~kg} / \mathrm{m}^{2}$ $(95 \% \mathrm{Cl}=0.1$ to $0.7, p=.017)$ compared to the control group; in the $24^{\text {th }}$ week of the program, there was no significant difference in BMI between the groups ( $p$ $>.05$ ), after variables were adjusted at baseline. Data are presented in Table 3.

Autonomous motivation of physical activity (RAI): In the $12^{\text {th }}$ and $24^{\text {th }}$ weeks of the program, only the intervention group had significantly increased in the amotivation score by 0.4 points $(95 \% \mathrm{Cl}=0.2$ to 0.5 , $p<.001)$ and 0.2 points $(95 \% \mathrm{Cl}=0.0$ to $0.4, p=.021)$ when compared to the control group, but the two groups were not significantly different for scores of RAI, external regulation, introjected regulation, identified regulation, or intrinsic regulation $(p>.05)$ after variables were adjusted at baseline. Data are presented in Table 4.

Autonomous motivation of dietary intakes (RAMI): In the $12^{\text {th }}$ week of the program, the intervention group's RAMI score was significantly decreased by 0.4 points $(95 \% \mathrm{Cl}=-0.6$ to $-0.1, p=.003)$, while its amotivation scores significantly increased by 0.4 points $(95 \% \mathrm{Cl}=0.1$ to $0.6, p=.004$ ) and the externally controlled motivation scores significantly increased by 0.3 points $(95 \% \mathrm{Cl}=$ 0.1 to $0.5, p=.010)$. There were no significant differences in the autonomous motivation score compared to the control group $(p>.05)$. All variables were adjusted at baseline. Data are presented in Table 5.

Similarly, in the $24^{\text {th }}$ week of the program, the intervention group's RAMI score significantly decreased by 0.3 points $(95 \% \mathrm{Cl}=-0.5$ to $0.0, p=.046)$, while its amotivation scores significantly increased by 0.3 points $(95 \% \mathrm{Cl}=0.0$ to $0.5, p=.046)$ and the externally controlled motivation scores significantly increased by 0.3 points ( $95 \% \mathrm{Cl}=0.0$ to $0.5, p=.025)$. There were no significant differences in the autonomous motivation score compared to the control group $(p>0.05)$. All variables were adjusted at baseline. Data are presented in Table 5. 


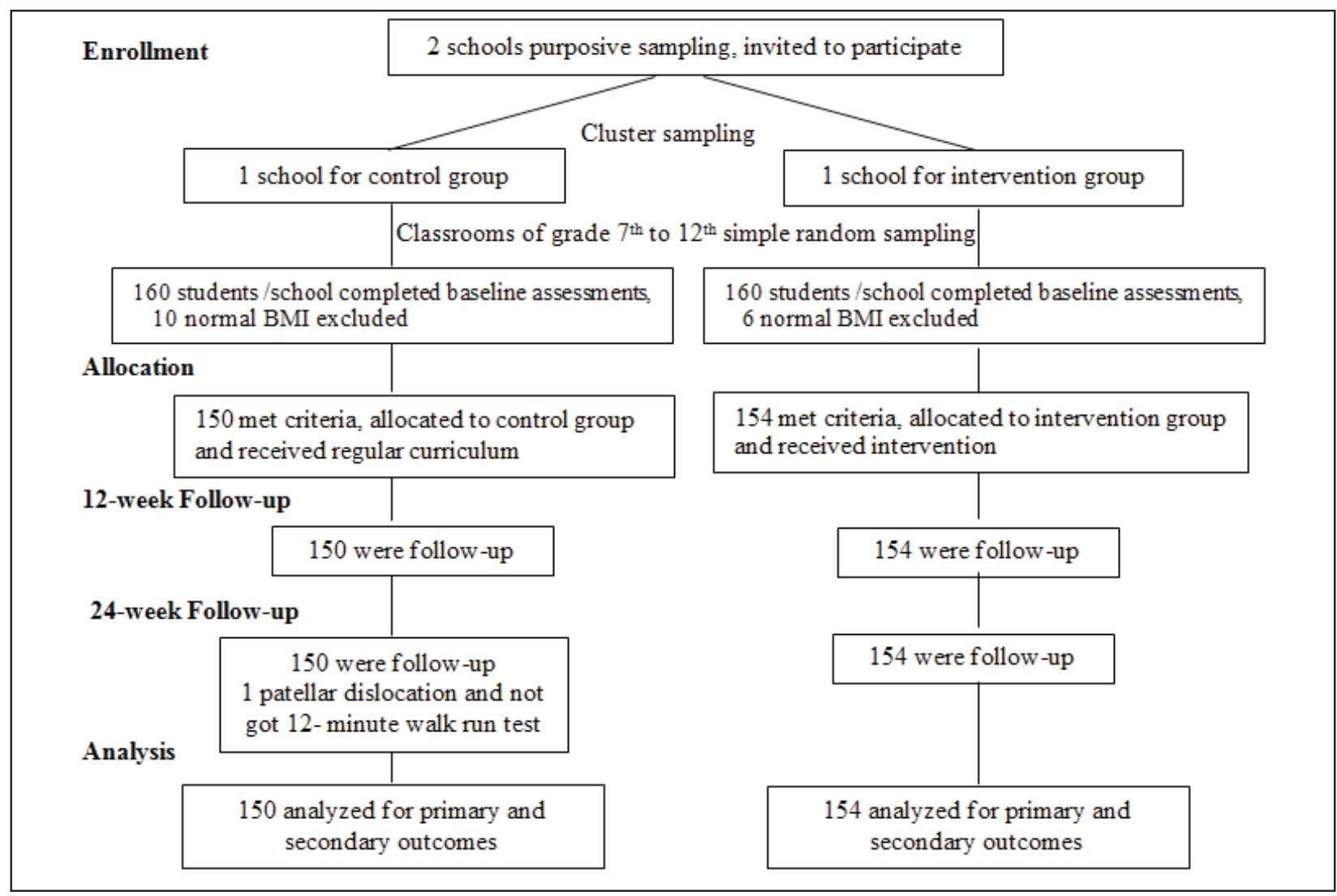

Fig 1: Study flow

Table 1: Examples of program component details

\begin{tabular}{|c|c|c|c|}
\hline Week/Topic & Concepts/theoretical-basis & Activities & $\begin{array}{l}\text { Duration } \\
\text { (minutes) }\end{array}$ \\
\hline \multicolumn{4}{|c|}{ Phrase 1: weight control (12 weeks) } \\
\hline $\begin{array}{l}1 \text { / overweight and } \\
\text { obesity }\end{array}$ & $\begin{array}{l}\text { - autonomous motivation (SDT) } \\
\text { - self-efficacy (SCT) } \\
\text { - self-regulation (SCT) } \\
\text { - observational learning (SCT) } \\
\text { - education }\end{array}$ & $\begin{array}{l}\text { - Introduction to weight reduction program } \\
\text { - Group relationship activities } \\
\text { - Teaching by using symbolic model, students brain } \\
\text { storming and set individual weight goal } \\
\text { - Students were assigned for weekly weight } \\
\text { recording, long } 1 \text { month for } 6 \text { months and offered } \\
\text { their interesting exercise and physical activity }\end{array}$ & 60 \\
\hline $\begin{array}{l}\text { physical activity } 3 \\
\text { days a week }\end{array}$ & & $\begin{array}{l}\text { - Students did exercise and physical activityby } \\
\text { choosing from their offering }\end{array}$ & 30 \\
\hline $\begin{array}{l}2 \text { / good shape by } \\
\text { exercise: part } 1\end{array}$ & $\begin{array}{l}\text { - autonomous motivation (SDT) } \\
\text { - self-efficacy (SCT) } \\
\text { - self-regulation (SCT) } \\
\text { - education }\end{array}$ & $\begin{array}{l}\text { - Teaching by using question emotional arousal } \\
\text { and slide presentation } \\
\text { - Students were assigned for calculated their own } \\
\text { BMI and physical activity daily self-record, long } 1 \\
\text { month for } 6 \text { months and offered their interesting } \\
\text { exercise and physical activity for } 2^{\text {nd }} \text { to } 6^{\text {th }} \text { week }\end{array}$ & 50 \\
\hline $\begin{array}{l}\text { physical activity3 } \\
\text { days a week }\end{array}$ & & $\begin{array}{l}\text { - Students did exercise and physical activity by } \\
\text { choosing from their offering }\end{array}$ & 30 \\
\hline 3/ Healthy diet & $\begin{array}{l}\text { - autonomous motivation (SDT) } \\
\text { - self-efficacy (SCT) } \\
\text { - self-regulation (SCT) } \\
\text { - education }\end{array}$ & $\begin{array}{l}\text { - Teaching by using question emotional arousal } \\
\text { and slide presentation } \\
\text { - Students were assigned for dietary consuming } \\
\text { daily self-record, long } 1 \text { month for } 6 \text { months }\end{array}$ & 40 \\
\hline $\begin{array}{l}\text { physical activity } 3 \\
\text { days a week }\end{array}$ & & $\begin{array}{l}\text { - Students did exercise and physical activity by } \\
\text { choosing from their offering }\end{array}$ & 30 \\
\hline
\end{tabular}


Table 1 cont...

\begin{tabular}{llll}
\hline Week/Topic & Concepts/theoretical-basis & Activities & $\begin{array}{l}\text { Duration } \\
\text { (minutes) }\end{array}$ \\
\hline Phrase 2: Follow-up (12 weeks) & & \\
\hline $\begin{array}{lll}\text { 13-15, 17-19 and } \\
\text { 21-24/physical }\end{array}$ & - autonomous motivation (SDT) & - Students did exercise and by physical activity by & 30 \\
activity 3 days a & - self-efficacy (SCT) & own self or their group & \\
week & - self-regulation (SCT) & - Follow-up (weight control, physical activity and \\
& & $\begin{array}{l}\text { dietary consuming behavior modification, stress } \\
\text { management and students daily book self-record }\end{array}$ \\
16,20 and 24 / & - self-efficacy (SCT) & $\begin{array}{l}\text { of dietary consuming and physical activity) was } \\
\text { using individual and group meetings, supporting, }\end{array}$ & 20 \\
follow-up & - self-regulation (SCT) & $\begin{array}{l}\text { monitoring, keeping a good communication and } \\
\text { counseling }\end{array}$ \\
\hline
\end{tabular}

Note. All topics taught by train teacher. Physical activity 3 days a week was on Monday, Wednesday and Friday.

Table 2: Participants' baseline characteristics $(n=304)$

\begin{tabular}{|c|c|c|c|c|c|}
\hline \multirow[t]{2}{*}{ Characteristics } & \multicolumn{2}{|c|}{$\begin{array}{l}\text { Intervention } \\
\text { group }(n=154)\end{array}$} & \multicolumn{2}{|c|}{ Control group $(n=150)$} & \multirow[t]{2}{*}{$\mathbf{p}$} \\
\hline & $\mathbf{n}$ & $(\%)$ & $\mathbf{n}$ & $(\%)$ & \\
\hline \multicolumn{6}{|l|}{ age (years) } \\
\hline $12-13$ & 42 & $(27.3)$ & 47 & (31.3) & $0.657^{b}$ \\
\hline $14-15$ & 50 & $(32.5)$ & 46 & $(30.7)$ & \\
\hline $16-17$ & 56 & $(36.3)$ & 48 & $(32.0)$ & \\
\hline $18-19$ & 6 & $(3.9)$ & 9 & $(6.0)$ & \\
\hline mean (SD) & \multicolumn{2}{|c|}{$14.9(1.70)$} & \multicolumn{2}{|c|}{$14.7(1.77)$} & $0.361^{a}$ \\
\hline \multicolumn{6}{|l|}{ Gender } \\
\hline male & 81 & $(52.6)$ & 79 & $(52.7)$ & $0.990^{\mathrm{b}}$ \\
\hline female & 73 & $(47.4)$ & 71 & $(47.3)$ & \\
\hline \multicolumn{6}{|l|}{ Grade } \\
\hline grade 7 & 23 & $(15.0)$ & 24 & $(16.0)$ & $0.975^{b}$ \\
\hline grade 8 & 34 & $(22.1)$ & 35 & $(23.3)$ & \\
\hline grade 9 & 21 & $(13.6)$ & 21 & $(14.0)$ & \\
\hline grade 10 & 30 & (19.5) & 24 & $(16.0)$ & \\
\hline grade 11 & 29 & $(18.8)$ & 27 & $(18.0)$ & \\
\hline grade 12 & 17 & $(11.0)$ & 19 & $(12.7)$ & \\
\hline \multicolumn{6}{|c|}{ Daily school pocket money (Baht/day) } \\
\hline $0-50$ & 145 & $(94.2)$ & 146 & $(97.3)$ & $0.257^{\mathrm{b}}$ \\
\hline $51-100$ & 9 & $(5.8)$ & 4 & $(2.7)$ & \\
\hline mean (SD) & \multicolumn{2}{|c|}{$39.2(14.2)$} & \multicolumn{2}{|c|}{$36.2(9.81)$} & $0.035^{\star a}$ \\
\hline
\end{tabular}

Note: a Comparison mean difference by using independent t-test;

${ }^{\mathrm{b} C}$ Comparison group variables by using chi-square test. 
Table 3: BMI change before and after program for the intervention and the control groups $(n=304)$

\begin{tabular}{|c|c|c|c|c|c|c|c|c|c|c|}
\hline & \multicolumn{2}{|c|}{$\begin{array}{l}\text { Intervention } \\
\text { group }(n=154)\end{array}$} & \multicolumn{2}{|c|}{$\begin{array}{l}\text { Control group } \\
(n=150)\end{array}$} & \multirow[t]{2}{*}{$\begin{array}{c}\text { Mean } \\
\text { difference }^{a}\end{array}$} & \multicolumn{5}{|c|}{$\begin{array}{c}\text { Adjusted } \\
\text { mean }\end{array}$} \\
\hline & Mean & (SD) & Mean & (SD) & & $95 \% \mathrm{Cl}$ & $p$ & difference $^{b}$ & $95 \% \mathrm{Cl}$ & $\mathbf{P}$ \\
\hline \multicolumn{11}{|l|}{ BMI $\left(\mathrm{kg} / \mathrm{m}^{2}\right)$} \\
\hline week 0 & 28.0 & (3.60) & 28.8 & $(4.11)$ & & & & & & \\
\hline week 12 & 27.7 & (3.67) & 28.2 & $(4.18)$ & -0.5 & $(-1.4,0.4)$ & .257 & 0.4 & $(0.1,0.7)$ & $0.017^{*}$ \\
\hline week 24 & 27.4 & (3.72) & 27.9 & $(4.15)$ & -0.5 & $(-1.4,0.4)$ & .273 & 0.3 & $(-0.1,0.7)$ & 0.127 \\
\hline
\end{tabular}

Note: Comparison of mean weight reduction at weeks 12 and 24 by using independent $t$-test.

a Comparison mean difference of weight reduction (the intervention - control groups) at weeks 12 and 24 by using simple linear regression;

'Adjusted parents' physical characteristics, daily school pocket money,physical activity behaviors, eating behavior, triceps skinfold thickness, subscapular skinfold thickness and BMI at baseline (week 0) by using multiple linear regression.

$95 \% \mathrm{Cl}=95 \%$ confidence interval.

Table 4: Scores of physical activity motivation before and after program of the intervention and the control groups $(n=304)$

\begin{tabular}{|c|c|c|c|c|c|c|c|c|c|c|}
\hline \multirow[t]{2}{*}{$\begin{array}{l}\text { Difference scores } \\
\text { of physical } \\
\text { activity motivation }\end{array}$} & \multicolumn{2}{|c|}{$\begin{array}{l}\text { Intervention } \\
\text { group } \\
(n=154)\end{array}$} & \multicolumn{2}{|c|}{$\begin{array}{l}\text { Control } \\
\text { group } \\
(n=150)\end{array}$} & \multirow[t]{2}{*}{$\begin{array}{c}\text { Mean } \\
\text { difference }^{a}\end{array}$} & \multicolumn{5}{|c|}{$\begin{array}{l}\text { Adjusted } \\
\text { mean }\end{array}$} \\
\hline & Mean & (SD) & Mean & (SD) & & $95 \% \mathrm{Cl}$ & $\mathbf{p}$ & difference $^{b}$ & $95 \% \mathrm{Cl}$ & $\mathbf{p}$ \\
\hline \multicolumn{11}{|l|}{ Amotivation } \\
\hline week 0 & 1.5 & $(0.88)$ & 1.4 & $(0.89)$ & & & & & & \\
\hline week 12 & 1.8 & $(0.88)$ & 1.4 & $(0.89)$ & 0.4 & $(0.2,0.6)$ & $<.001^{*}$ & 0.4 & $(0.2,0.5)$ & $<.001^{*}$ \\
\hline week 24 & 1.8 & $(0.79)$ & 1.6 & $(0.92)$ & 0.2 & $(0.1,0.4)$ & $.013^{*}$ & 0.2 & $(0.0,0.4)$ & $.021^{*}$ \\
\hline \multicolumn{11}{|l|}{ External regulation } \\
\hline week 0 & 1.9 & $(0.82)$ & 1.8 & $(0.85)$ & & & & & & \\
\hline week 12 & 1.9 & $(0.85)$ & 1.7 & $(0.86)$ & 0.1 & $(-0.1,0.3)$ & .181 & 0.1 & $(-0.1,0.3)$ & .345 \\
\hline week 24 & 1.8 & $(0.71)$ & 1.8 & $(0.81)$ & 0 & $(-0.2,0.1)$ & .670 & -0.1 & $(-0.2,0.1)$ & .452 \\
\hline \multicolumn{11}{|l|}{ Introjected regulation } \\
\hline week 0 & 1.9 & $(0.89)$ & 1.9 & $(0.79)$ & & & & & & \\
\hline week 12 & 1.9 & $(0.86)$ & 1.9 & $(0.76)$ & 0 & $(-0.1,0.2)$ & .665 & 0 & $(-0.2,0.2)$ & .977 \\
\hline week 24 & 1.9 & $(0.81)$ & 1.9 & $(0.80)$ & 0 & $(-0.1,0.2)$ & .547 & 0 & $(-0.1,0.2)$ & .699 \\
\hline \multicolumn{11}{|l|}{ Identified regulation } \\
\hline week 0 & 2.5 & $(0.78)$ & 2.6 & $(0.72)$ & & & & & & \\
\hline week 12 & 2.4 & $(0.67)$ & 2.4 & $(0.67)$ & 0 & $(-0.1,0.2)$ & .880 & 0 & $(-0.1,0.2)$ & .564 \\
\hline week 24 & 2.4 & $(0.64)$ & 2.5 & $(0.63)$ & -0.1 & $(-0.2,0.1)$ & .342 & 0 & $(-0.2,0.1)$ & .528 \\
\hline \multicolumn{11}{|l|}{ Intrinsic regulation } \\
\hline week 0 & 2.6 & $(0.83)$ & 2.7 & $(0.91)$ & & & & & & \\
\hline week 12 & 2.6 & $(0.72)$ & 2.6 & $(0.85)$ & 0 & $(-0.2,0.2)$ & .805 & 0.1 & $(-0.1,0.2)$ & .488 \\
\hline week 24 & 2.5 & $(0.74)$ & 2.6 & $(0.73)$ & -0.1 & $(-0.3,0.0)$ & .107 & -0.1 & $(-0.3,0.1)$ & .216 \\
\hline \multicolumn{11}{|l|}{ RAI } \\
\hline week 0 & 2.7 & $(5.19)$ & 3.9 & $(5.55)$ & & & & & & \\
\hline week 12 & 1.5 & $(5.16)$ & 3.0 & $(5.96)$ & -1.5 & $(-2.8,-0.3)$ & $.017^{*}$ & -1.1 & $(-2.2,0.1)$ & .071 \\
\hline week 24 & 1.3 & $(4.96)$ & 2.5 & $(5.75)$ & -1.2 & $(-2.4,0.1)$ & .069 & -0.8 & $(-2.0,0.3)$ & .133 \\
\hline
\end{tabular}

Note: Comparison of mean changed in physical activity motivation at weeks 12 and 24 by using independent $t$-test.

a Comparison mean difference of physical activity motivation change (the intervention - control groups) at weeks 12 and 24 by using simple linear regression;

${ }^{\mathrm{b}}$ Adjusted for knowledge, school level, Identified regulation, Intrinsic regulation, RAI and that motivation subscales at baseline (week 0 ) by using multiple linear regression.

95\% Cl $=95 \%$ confidence interval. 
Table 5: Scores of dietary intakes motivation before and after the program for intervention and control groups $(n=304)$

\begin{tabular}{|c|c|c|c|c|c|c|c|c|c|c|}
\hline \multirow[t]{2}{*}{$\begin{array}{l}\text { Difference } \\
\text { scores of } \\
\text { dietary intakes } \\
\text { motivation }\end{array}$} & \multicolumn{2}{|c|}{$\begin{array}{l}\text { Intervention } \\
\text { group } \\
(n=154)\end{array}$} & \multicolumn{2}{|c|}{$\begin{array}{l}\text { Control } \\
\text { group } \\
(n=150)\end{array}$} & \multirow[t]{2}{*}{$\begin{array}{c}\text { Mean } \\
\text { difference }^{a}\end{array}$} & \multicolumn{5}{|c|}{$\begin{array}{l}\text { Adjusted } \\
\text { mean }\end{array}$} \\
\hline & Mean & (SD) & Mean & (SD) & & $95 \% \mathrm{Cl}$ & $p$ & difference $^{b}$ & $95 \% \mathrm{Cl}$ & $\mathbf{p}$ \\
\hline \multicolumn{11}{|l|}{ Amotivation } \\
\hline week 0 & 3.4 & $(1.20)$ & 3.5 & $(1.25)$ & & & & & & \\
\hline week 12 & 3.7 & $(1.14)$ & 3.3 & $(1.14)$ & 0.4 & $(0.2,0.7)$ & $.001^{*}$ & 0.4 & $(0.1,0.6)$ & $0.004^{*}$ \\
\hline week 24 & 3.6 & $(1.14)$ & 3.4 & $(1.18)$ & 0.2 & $(0.0,0.5)$ & .074 & 0.3 & $(0.0,0.5)$ & $0.046^{*}$ \\
\hline \multicolumn{11}{|c|}{ Externally controlled motivation } \\
\hline week 0 & 3.9 & $(1.08)$ & 3.8 & $(1.11)$ & & & & & & \\
\hline week 12 & 3.9 & $(1.09)$ & 3.6 & $(1.03)$ & 0.3 & $(0.1,0.5)$ & $.015^{*}$ & 0.3 & $(0.1,0.5)$ & $0.010^{*}$ \\
\hline week 24 & 3.9 & $(0.99)$ & 3.6 & $(1.02)$ & 0.2 & $(0.0,0.6)$ & .052 & 0.3 & $(0.0,0.5)$ & $0.025^{*}$ \\
\hline \multicolumn{11}{|c|}{ Autonomous motivation } \\
\hline week 0 & 4.7 & (1.91) & 4.6 & $(1.30)$ & & & & & & \\
\hline week 12 & 4.4 & $(1.13)$ & 4.5 & $(1.12)$ & -0.1 & $(-0.3,0.3)$ & .524 & 0 & $(-0.3,0.2)$ & 0.713 \\
\hline week 24 & 4.4 & $(1.10)$ & 4.4 & $(1.16)$ & 0 & $(-0.3,0.2)$ & .866 & 0 & $(-0.3,0.2)$ & 0.947 \\
\hline \multicolumn{11}{|l|}{ RAMI } \\
\hline week 0 & 0.8 & $(1.28)$ & 0.8 & $(1.24)$ & & & & & & \\
\hline week 12 & 0.5 & $(1.04)$ & 0.9 & $(1.22)$ & -0.4 & $(-0.6,-0.1)$ & $.004^{*}$ & -0.4 & $(-0.6,-0.1)$ & $0.003^{*}$ \\
\hline week 24 & 0.5 & $(1.16)$ & 0.8 & $(1.28)$ & -0.3 & $(-0.5,0.0)$ & .063 & -0.3 & $(-0.5,0.0)$ & $0.046^{*}$ \\
\hline
\end{tabular}

Note. Comparison of mean dietary intake motivation change at weeks 12 and 24 by using independent $t$-test.

a Comparison mean difference of dietary intake motivation at weeks 12 and 24 by using simple linear regression;

${ }^{\mathrm{b}}$ Adjusted for knowledge, school level, Identified regulation, Intrinsic regulation, RAI and that motivation subscales at baseline (week 0) by using multiple linear regression.

$95 \% \mathrm{Cl}=95 \%$ confidence interval.

\section{Discussion}

A multi component WRP based on SCT and SDT was developed to evaluate its effects on BMI and autonomous motivation toward physical activity and dietary intakes among overweight and obese Thai students. A multiple linear regression found no statistical differences in adjusted means of BMI and autonomous motivation of physical activity and dietary intake in either participant group. The intervention group showed a 0.4 smaller increase in BMI than the control group, which is similar to the PRALIMAP project's 0.11 lower increase ${ }^{34}$.

Meanwhile, the intervention group showed a 0.4 greater decrease in autonomous motivation of dietary intakes (RAMI) than the control group, but no difference in autonomous motivation of physical activity (RAI). Increased amotivation, one form of motivation calculated for RAMI and RAI composite scores, was evident for both autonomous motivation of dietary intakes and physical activity. Previous research has indicated that programs might pressure youth to become physically active $^{35}$; this might have influenced the RAMI and RAI scores in the current study.
This study also found that students did not continuously self-record for physical activity and dietary intakes in their individual notebooks due to the low levels of self-regulation and self-control. A previous study described the correlation among amotivation, self-regulation and self-control, and the inability to lose weight in the short term ${ }^{36}$. Therefore, using external rewards and praise (e.g., a colorful cartoon bundle and compliment sticker) twice during the program (in the intervention group) to create motivation might not be enough to make students with a high level of amotivation change their behavior and reduce their weight. No significant differences emerged in the externally controlled motivations before and after the experiment, meaning behaviors can be maintained in the short term, but not the long term ${ }^{37}$, Externally controlled motivation is a controlled form of motivation created by reward ${ }^{38}$. This study found that the intervention and control groups showed no difference in eating based on externally controlled motivation.

Moreover, participants in this study lacked the readiness to change, and many lacked motivation for exercise and food intake. High amotivation scores were 
related to low autonomous motivation. At the $12^{\text {th }}$ and $24^{\text {th }}$ weeks, the intervention group had an exercise amotivation score ( $\geq 2$ points, total 4 points) of $74.5 \%$ and $73.3 \%$ and an eating amotivation score ( $\geq 3$ points, total 6 points) of $87.7 \%$ and $86.1 \%$, respectively.

Interestingly, the results indicated that BMI was related to autonomous motivation. The intervention group's BMI was significantly lower at weeks 12 and $24[27.7( \pm 3.67), p=0.001$ and $27.4( \pm 3.72), p$ $<0.0001$ ] than the baseline (data not shown), inferring that they were still obese. Individuals' autonomous motivation of physical activity and dietary intakes did not increase in the obesity group. Hwang and $\mathrm{Kim}^{39}$ found that overweight and obese adolescents had lower scores on intrinsic motivation but higher scores on demotivation and extrinsic motivation than normal weight adolescents. The school had many extra-school learning opportunities; participants who joined the school's and program's activities at the same time might have experienced stress and coped poorly, resulting in no increase in the autonomous motivation of physical activity and dietary intakes.

The WRP showed no effect on BMI and autonomous motivation of physical activity and dietary intakes. Various explanations may account for this result. First, the adherence rate was low. Adherence and completion of the intervention are correlated with positive outcomes ${ }^{40}$. This study's low adherence rate stemmed from unplanned changes in school schedules or extra learning and teaching activities (e.g., national standardized test preparation and religious and traditional activities). During the initial weight control phase, $23.1 \%$ to $62.8 \%(n=78)$ of middle school students joined the 8-period classroom education project, compared to $13.2 \%$ to $56.6 \%(n=76)$ of high school students; $10.3 \%$ to $75.6 \%$ of middle school students joined physical activity 3 times a week (through week 12) compared to $6.6 \%$ to $26.3 \%$ of high school students. During the follow-up phase (2 times), $41.0 \%$ to $48.7 \%$ of middle school students and $30.3 \%$ to $18.4 \%$ of high school students participated (data not shown).

Second, some parts of the motivational questionnaires showed lower reliability. Instruments for measuring autonomous motivation of physical activity and dietary intakes of Thai adolescents are quite limited. Cross-cultural motivation tools might be less sensitive with Thai youths.

Third, WRPs can help children and adolescents succeed in losing weight over 6 to 12 months ${ }^{13}$. Such programs require a minimum of 24 weeks ( 6 months). The intervention group's lacked the readiness to change and motivation for exercise and food intake were a different finding from previous studies, which found that longer WRPs improved autonomous motivation. Verloigneet et $\mathrm{al}^{16}$. found that 177 obese participants (mean age 15.1 years) who joined a 10-month exercise and dietary program showed increasing intrinsic motivation. Saavedra et al. ${ }^{17}$ found that participants in an exercise-only program and exercise and dietary program for 6 months to 3 years showed increased levels of intrinsic motivation and exercise; such participation influenced the persistence of internal motivation when engaged in the program. This finding is consistent with SDT's assertion that participating in activities for a long period contributes to intrinsic motivation ${ }^{26,41}$. The currently studied 24-week research program might not have been long enough to make changes in students' dietary self-determination motivation.

Finally, the internal and external school environments (i.e., food shops) were less controlled. These changing environments make this experimental design less appropriate for field study. The intervention group was exposed to unhealthy foods more often than the control group through a 24-hour convenience store near the intervention school's entrance and a temporary market selling unhealthy foods near the school. These stores were not accessible from the control school. A greater availability of convenience stores leads to higher $\mathrm{BMI}$ in adolescents ${ }^{42}$.

Despite the study's strengths (i.e., the teacher leading this program participated in the program and lesson plan development processes, taught all eight sessions himself, and specialized in teaching middle and high school students), several limitations exist. For example, the experimental study results might not be generalizable to both public and private secondary schools in Thailand. However, when implementing the program, many extra school activities and schools did not plan to change school teaching periods, thereby affecting an important reduction in participation program activities. In addition, it was difficult to combine middle and high school students into one classroom due to different schedules.

\section{Conclusions}

The WRP based on SDT and SCT provided insufficient evidence of effects on BMI and autonomous motivation among overweight and obese secondary school students. Future studies should incorporate program activities with core teaching activities. They should also consider using sensitive autonomous motivation tools for Thai youths, taking long period of the program and creating supportive environments for weight loss and weight control in schools. 


\section{References}

1. Wang $\mathrm{Y}$, Lim $\mathrm{H}$. The global childhood obesity epidemic and the association between socio-economic status and childhood obesity. Int Rev Psychiatry 2012;24(3):176-88. doi: 10.3109/09540261.2012.688195

2. Fryar CD, Carroll MD, Ogden CL. Prevalence of Obesity Among Children and Adolescents: United States, Trends 1963-1965 Through 2009-2010. Health E-Stat 2012(september):1-6.

3. Liou TH, Huang YC, Chou P. Prevalence and secular trends in overweight and obese Taiwanese children and adolescents in 1991-2003. Ann Hum Biol 2009;36(2):17685. doi: $10.1080 / 03014460802691174$

4. Nguyen PV, Hong TK, Hoang T, Nguyen DT, Robert AR. High prevalence of overweight among adolescents in Ho Chi Minh City, Vietnam. BMC Public Health 2013;13:141. doi: 10.1186/1471-2458-13-141

5. Mo-suwan L. Lesson 8 Nutrition on children. In: Aeplakorn W, editor. The 4th National Health Examination Survey Report, year 2008-2009: Children Health. Nonthaburi 2009.

6. Tsiros MD, Olds T, Buckley JD, Grimshaw P, Brennan $\mathrm{L}$, Walkley $\mathrm{J}$, et al. Health-related quality of life in obese children and adolescents. Int J Obes 2009;33(4):387400. doi: $10.1038 / i j o .2009 .42$

7. Reilly JJ, Methven E, McDowell ZC, Hacking B, Alexander D, Stewart L, et al. Health consequences of obesity. Arch Dis Child 2003;88(9):748-52.

8. Singh AS, Mulder C, Twisk JW, van Mechelen W, Chinapaw MJ. Tracking of childhood overweight into adulthood: a systematic review of the literature. Obes Rev 2008;9(5):474-88. doi: 10.1111/j.1467789X.2008.00475.X

9. Neumark-Sztainer DR, Friend SE, Flattum CF, Hannan PJ, Story MT, Bauer KW, et al. New moves-preventing weight-related problems in adolescent girls a grouprandomized study. Am J Prev Med 2010;39(5):421-32. doi: 10.1016/j.amepre.2010.07.017

10. Lubans DR, Morgan PJ, Okely AD, Dewar D, Collins $\mathrm{CE}$, Batterham $\mathrm{M}$, et al. Preventing Obesity Among Adolescent Girls: One-Year Outcomes of the Nutrition and Enjoyable Activity for Teen Girls (NEAT Girls) Cluster Randomized Controlled Trial. Arch Pediatr Adolesc Med 2012;166(9):821-7. doi: 10.1001/archpediatrics.2012.41

11. Melnyk BM, Small L, Morrison-Beedy D, Strasser A Spath L, Kreipe R, et al. The COPE Healthy Lifestyles TEEN program: feasibility, preliminary efficacy, \& lessons learned from an after school group intervention with overweight adolescents. J Pediatr Health Care 2007;21(5):315-22. doi: 10.1016/j.pedhc.2007.02.009

12. Johnston CA, Tyler C, Fullerton G, McFarlin BK, Poston WS, Haddock CK, et al. Effects of a school-based weight maintenance program for Mexican-American children results at 2 years. Obesity 2010;18(3):542-7. doi: 10.1038/oby.2009.241
13. Reinehr T. Effectiveness of lifestyle intervention in overweight children. Proc Nutr Soc 2011;70(4):494-505. doi: 10.1017/S0029665111000577

14. Wilson DK, Evans AE, Williams J, Mixon G, Sirard JR, Pate R. A preliminary test of a student-centered intervention on increasing physical activity in underserved adolescents. Ann Behav Med 2005;30(2):119-24. doi: 10.1207/s15324796abm3002_4

15. Contento IR, Koch PA, Lee $\mathrm{H}$, Calabrese-Barton A. Adolescents demonstrate improvement in obesity risk behaviors after completion of choice, control and change, a curriculum addressing personal agency and autonomous motivation. J Am Diet Assoc 2010;110(12):1830-9. doi: 10.1016/j.jada.2010.09.015

16. Verloigne M, De Bourdeaudhuij I, Tanghe A, D'Hondt E, Theuwis L, Vansteenkiste M, et al. Self-determined motivation towards physical activity in adolescents treated for obesity: an observational study. Int J Behav Nutr Phys Act 2011;8:97. doi: 10.1186/1479-5868-8-97

17. Saavedra JM, García-Hermoso A, Escalante $Y$, Domínguez AM. Self-determined motivation, physical exercise and diet in obese children: A three-year followup study Int J Clin Health Psychol 2014;14:195-201.

18. Riiser $\mathrm{K}$, Londal $\mathrm{K}$, Ommundsen $\mathrm{Y}$, Smastuen $\mathrm{MC}$, Misvaer N, Helseth S. The outcomes of a 12-week Internet intervention aimed at improving fitness and health-related quality of life in overweight adolescents: the Young \& Active controlled trial. PloS one 2014;9(12):e114732. doi: 10.1371/journal.pone.0114732

19. Bandura A. Social Foundations of Thought and Action. Prentice Hall: Englewood Cliffs, NJ; 1986.

20. Bandura A. Human agency in social cognitive theory. Am Psychol 1989;44(9):1175-84.

21. Deci EL, Ryan RM. The 'what' and 'why' of goal pursuits: Human needs and the self-determination of behavior. Psychol Inq 2000;11(4):227-68.

22. Duangchan P. Effectiveness of behavioral intervention program applying self-control and self-efficacy for modifying psychological, behavioral, and physical variables among schoolchildren at risk of type 2 diabetes, Ramkhamhaeng University Demonstration School, Bangkok.: Doctural dissertation. Srinakharinwirot University; 2010.

23. Teerarungsikul N, Phuphaibul R, Loveland-Cherry CJ, Pookboonmee R, Kijboonchoo K, Nityasuddhi D. Effectiveness of a Physical Activity Promotion Program on Perceived Self-efficacy, Physical Activity and Physical Fitness among Thai Adolescent Girls. Thai J Nurs Res 2009;13(2):81-94.

24. Kosuwan S, Suntayakorn C, Wannapornsiri C, Siripornpibul T. The Effect of Self-Efficacy Enhancing Program on Perceived Self Practice and Body Weight among Overweight Female Adolescent Students, Amphor Lomsak, Phetchaboon Province. J Nurs Sci Naresuan Univ 2007;1(1):32-46. 
25. Silva MN, Vieira PN, Coutinho SR, Minderico CS, Matos MG, Sardinha LB, et al. Using self-determination theory to promote physical activity and weight control: a randomized controlled trial in women. J Behav Med 2010;33(2):110-22. doi: 10.1007/s10865-009-9239-y

26. Deci EL, Ryan RM. Intrinsic motivation and selfdetermination in human behavior. New York: Plenum; 1985

27. Ryan RM, Deci EL. Self-determination theory and the facilitation of intrinsic motivation, social development, and well-being. Am 28. Moher D, Hopewell S, Schulz KF, Montori V, Gotzsche PC, Devereaux PJ, et al. CONSORT 2010 explanation and elaboration updated guidelines for reporting parallel group randomised trials. BMJ 2010;340:C869. doi: 10.1136/ bmj.c869

29. de Onis M, Onyango AW, Borghi E, Siyam A, Nishida C, Siekmann J. Development of a WHO growth reference for school-aged children and adolescents. Bull World Health Organ 2007;85(9):660-7.

30. Markland D, Tobin V. A modification to the Behavioural Regulation in Exercise Questionnaire to include assessment of amotivation. J Sport Exerc Psychol 2004;26:191-96

31. Exercise Motivation Measurement: The Behavioural Regulation in Exercise Questionnaire, Scoring the BERQ and BREQ-2. [cited 2013 February 18] Available from: http://pages.bangor.ac.uk/ pes004/ exercise_motivation/breq/breq.htm.

32. No-in K, Tuicomepee A, Jiamjarasrangsi W, Sithisarankul $\mathrm{P}$. Validation of behavioral regulation in exercise questionnaire-2 (BREQ-2) and dietary selfregulation (DSR) in overweight high school students in Thailand. J Health Res 2015;29(4):269-76.

33. The Self-Regulation Questionnaires. n.d. [cited 2013 February 18]. Available from: http://www. selfdeterminationtheory.org/questionnaires/10questionnaires $/ 48$
34. Bonsergent E, Agrinier N, Thilly N, Tessier S, Legrand $\mathrm{K}$, Lecomte $\mathrm{E}$, et al. Overweight and obesity prevention for adolescents: a cluster randomized controlled trial in a school setting. Am J Prev Med 2013;44(1):30-9. doi: 10.1016/j.amepre.2012.09.055

35. Markland D, Ingledew DK. The relationships between body mass and body image and relative autonomy for exercise among adolescent males and females. Psychol Sport Exerc 2007;8:836-53.

36. Teixeira PJ, Patrick $\mathrm{H}$, Mata J. Why we eat what we eat: the role of autonomous motivation in eating behaviour regulation. Nutr Bull 2011;36:102-7.

37. Teixeira PJ, Carraca EV, Markland D, Silva MN, Ryan RM. Exercise, physical activity, and self-determination theory: a systematic review. Int J Behav Nutr Phys Act 2012;9:78. doi: 10.1186/1479-5868-9-78

38. Harris J, Standage $H$. The effect of autonomous and controlled motives on eating dysregulation: Implications for individuals classified as underweight, overweight or obese. Rev Eur Psychol Appl 2014;64(2):43-51.

39. Hwang J, Kim YH. Physical activity and its related motivational attributes in adolescents with different BMI. Int J Behav Med 2013;20(1):106-13. doi: 10.1007/s12529-011-9196-z

40. Moroshko I, Brennan L, O'Brien P. Predictors of dropout in weight loss interventions: a systematic review of the literature. Obes Rev 2011;12(11):912-34. doi: 10.1111/j.1467-789X.2011.00915.x

41. Verstuyf J, Patrick H, Vansteenkiste M, Teixeira PJ. Motivational dynamics of eating regulation: a selfdetermination theory perspective. Int J Behav Nutr Phys Act2012;9:21. doi: 10.1186/1479-5868-9-21

42. Powell LM, Auld MC, Chaloupka FJ, O'Malley PM, Johnston LD. Associations between access to food stores and adolescent body mass index. $A m \mathrm{~J}$ Prev Med 2007;33(4 Suppl):S301-7. doi: 10.1016/j. amepre.2007.07.007 Psychol 2000;55(1):68-78. 